\title{
PDGF-BB homodimer serum level - a good indicator of the severity of alcoholic liver cirrhosis
}

\author{
Ewa Kurys-Denis ${ }^{1, A-F}{ }^{\oplus}$, Andrzej Prystupa ${ }^{1, A-B, E-F}{ }^{\oplus}$, Dorota Luchowska-Kocot ${ }^{1, B-C, F}{ }^{\text {, }}$, \\ Witold Krupski ${ }^{1, B, F \oplus}$, Hanna Bis-Wencel ${ }^{2, D, F \oplus}$, Lech Panasiuk ${ }^{3, C, F} \oplus$ \\ ${ }^{1}$ Medical University, Lublin, Poland \\ ${ }^{2}$ University of Life Sciences, Lublin, Poland \\ ${ }^{3}$ Institute of Rural Health, Lublin, Poland \\ A - Research concept and design, B - Collection and/or assembly of data, C - Data analysis and interpretation, \\ $D$ - Writing the article, E - Critical revision of the article, F - Final approval of article
}

Kurys-Denis E, Prystupa A, Luchowska-Kocot D, Krupski W, Bis-Wencel H, Panasiuk L. PDGF-BB homodimer serum level - a good indicator of the severity of alcoholic liver cirrhosis. Ann Agric Environ Med. 2020; 27(1): 80-85. DOI: 10.26444/aaem/115997

\section{Abstract}

Introduction. Liver cirrhosis is a chronic disease in which progressive fibrosis is noted. This process leads to changed architectonics of the liver parenchyma and the appearance of regenerative nodules, all of which are caused by pathological activation of the hepatic stellate cells. This process is enhanced on a molecular level by many cytokines, with platelet-derived growth factors (PDGFs) playing the key role.

Objective. The aim of the study was to assess serum concentrations of PDGFs active biodymers (PDGF-AA, PDGF-BB and PDGF-AB) in patients with alcoholic liver cirrhosis, and to correlate them with the stage of disease.

Materials and method. 64 patients with alcoholic cirrhosis and a control group of 16 healthy individuals were analysed. Liver cirrhosis was determined based on clinical image, history of the patients' alcohol consumption, laboratory findings and abdominal ultrasonography. The serum PDGF-AA, PDGF-BB and PDGF-AB concentrations were determined using ELISA kits.

Results. Serum concentration of PDGF-AA and PDGF-BB homodimers increases in patients with alcoholic liver cirrhosis $(p=0.034$ and $p<0.0001$, respectively), unlike the serum concentration of PDGF-AB heterodimer ( $p>0.05)$. When the stage of the disease increases, the concentrations of PDGF-AA and PGFD-BB in blood also oncrease. Furthermore, the serum level of both PDGF-AA and PDGF-BB correlates significantly with the severity of alcoholic liver cirrhosis (measured by Pugh-Child's scale), the correlation being stronger in the case of PDGF-BB levels than PDGF-AA $(R=0.28 ; p=0.027$ and $R=0.26 ; p=0.038$, respectively).

Conclusions. The plasma levels of PDGF-AA and -BB may be indicators of alcohol-induced liver fibrosis process, and might be considered as future possible treatment targets, with PDGF-BB levels being an even better indicator than PDGF-AA levels.

\section{Key words}

alcohol; liver cirrhosis, Child-Pugh score, platelet derived growth factor AA, platelet growth factor AB, platelet derived growth factor BB

\section{INTRODUCTION}

In chronic liver cirrhosis, progressive fibrosis takes place, leading to impaired architectonics of the liver parenchyma and the appearance of regenerative nodules. There are different diseases and toxins that can be responsible for causing chronic liver damage, among which alcohol is one of the most important, followed by infections with hepatotropic viruses [1]. Europe is considered to be one of the geographical regions with the highest alcohol consumption, although consumption decreased in the 1990s, to increase again and finally stabilise at high levels at the beginning of the $21^{\text {st }}$ century, depending on the country [2].

The key process in the progression of liver fibrosis leading in time to liver cirrhosis involves the pathological activation of hepatic stellate cells (HSCs) [3]. Activated HSCs change in morphology and behaviour, transforming themselves from a

Address for correspondence: Ewa Kurys-Denis, Medical University, Lublin, Poland E-mail: ewa.kurys-denis@umlub.pl

Received: 30.08 .2019 ; accepted: 05.12.2019; first published: 25.01 .2020 neuronal-like to a miofibroblast-like morphology, and start to produce an extracellular matrix (ECM). The activated stellate cells also produce, among other substances, tissue inhibitors of metaloproteinases (TIMPs), which in turn enable the activation of matrix metaloproteinase (MMP) and further enhance ECM deposition in the liver. The ECM contains mainly collagen type $\mathrm{I}$, the overproduction of which is a direct and basic cause of liver fibrosis [4].

This process is enhanced on a molecular level by many pro-inflammatory, proangiogenic and profibrotic cytokines involving, among others, platelet-derived growth factors (PDGFs), tumour necrosis factor $\alpha$ (TNF- $\alpha$ ), transforming growth factor $\beta$ (TGF- $\beta$ ), interleukin 6 (IL-6), fibroblast growth factors like 19 (FGF-19), leptin and many others, issued by damaged liver cells [5]. The strongest cytokines causing activation of HSCs are PDGFs and TGF- $\beta$. HSCs can also be activated by reactive oxygen species (ROS) issued during the metabolism of ethanol or other toxins, making oxidative stress a second line of activation factors of HSCs. Thus, direct damage of hepatic cells by a liver damaging agent leads to the production of multiple cytokines activating 
HSCs, while on the other hand, activated HSCs are able to enhance their own activation by further producing growth factors such as PDGFs and TGF- $\beta$.

PDGFs take part directly in liver fibrosis and cirrhosis and have been studied extensively in the literature [6-14]. There are 4 different PDGF isoforms or subunits (A, B, C and D) that act as bio-active dimmers, and via a disulfide-bond linkage create 5 homologous or heterogeneous bio-polymers - PDGF-AA, -BB, -AB, -CC, and -DD, [7,8]. Among these isoforms, PDGF-A has a molecular weight of $16 \mathrm{kDa}$, consists of 211 amino acids, and is located at the chromosomal site 7p22. PDGF-A has been found to have a high expression in the muscle, aorta and heart. The other isoform - PDGF-B - has a molecular weight of $14 \mathrm{kDa}$, is located at the chromosomal site 22q13 and exhibits high expression in the placenta and heart. PGDFs A and B link together to form 3 homologous or heterologous dipolymers - PDGF-AA, - BB and - AB, which in turn bind as homo- or heterodimers to 2 possible receptors - PDGF $\alpha$ and $\beta$. PDGF-AA primarily binds with platelet derived growth factor receptor $\alpha \alpha$ (PDGFR- $\alpha \alpha)$ in order to control the proliferation and chemotaxis of cells. PDGF-AB in turn, binds with either PDGFR-a $\alpha$ or platelet derived growth factor receptor $\alpha \beta$ (PDGFR- $\alpha \beta$ ), whereas the PDGF-BB binds with all receptor subunits (PDGFR- $\alpha \alpha$, $-\alpha \beta$ and $-\beta \beta)$. Stimulated PDGFR- $\alpha \beta$ and $-\beta \beta$ take part in boosting collagen synthesis and cellular adhesion [8]. The PDGF-B isoform is thought to be the most serious mitogen for HSCs $[9,10]$. The blood concentration of PDGF-BB was found to positively correlate with the degree of liver fibrosis and inflammation in chronic B hepatitis patients [11].

Some authors, however, have shown that PDGF-A could also be treated as an important profibrogenic agent, exercising its action via TGF- $\beta 1$ induction. Recently, the platelet-derived growth factor A mRNA has been found to correlate with the liver fibrosis grade in chronic hepatitis $\mathrm{C}$ [12]. The other 2 PDGFs - PDGF-C and PDGF-D - seem to be implicated more in vascular pathologies, for example, atherosclerosis or stroke. A different sequence of serum cytokines, including PDGF-BB, TIMP-1 and MMP, has been proposed in screening for liver fibrosis [12-14].

Although a great deal is known about the mechanisms responsible for liver fibrosis and cirrhosis and the role of PDGFs in it, the exact molecular presence of PDGF dimers specifically in alcoholic cirrhotic disease has not been fully investigated.

\section{OBJECTIVE}

The aim of the study was to examine the correlation between the stage of alcoholic liver cirrhosis and subtypes of bioactive dimers of the profibrotic cytokines (PDGFs) in order to find the best serum indicator of alcohol-induced liver fibrosis process and future possible treatment targets.

\section{MATERIALS AND METHOD}

64 patients from the Lublin Region in Eastern Poland were included who were diagnosed with alcoholic liver cirrhosis due to an over-consumption of alcohol for many years. The assessment of alcohol consumption was estimated on the basis of a self-reported-survey. The cirrhotic patients had abused alcohol for a mean of $12 . \pm 7.8$ years, with the quantity of alcohol being consumed equal to a daily consumption of $5.1 \pm 2.8$ drinks in men and $4.5 \pm 2.6$ drinks y in women. In the survey it was assumed that one drink equaled $10 \mathrm{~g}$ of pure alcohol. Patients with viral, autoimmune diseases and alcoholic hepatitis were excluded from the study. Liver cirrhosis was diagnosed on the basis of clinical picture, patient's history of heavy alcohol consumption, laboratory results and abdominal ultrasonography. The stage of liver cirrhosis was assessed with the use of Child-Turcotte-Pugh criteria (Child-Pugh score) taking into account 5 features: the laboratory results of bilirubin, albumin, INR, the presence of ascites (determined by ultrasonography) and encephalopahy (graded by a neurologist) [15]. A score of 1,2, or 3 was given to each measure, with 3 being the most severe. Class A of ChildPugh classification involved patients with 5-6 points, Class B - 7-9 points and class $C-10-15$ points. Based on these criteria, the patients were classified into 3 groups: $1^{\text {st }}-\mathrm{P}-\mathrm{Ch} \mathrm{A}$, 17 patients with stage $A, 2^{\text {nd }}-\mathrm{P}-\mathrm{Ch} B,-26$ patients with stage $\mathrm{B}$ and $3^{\text {rd }}-\mathrm{P}-\mathrm{Ch} \mathrm{C}-21$ patients with stage $\mathrm{C}$ liver cirrhosis. The control group comprised 16 healthy individuals who did not abuse alcohol and had no liver disease. None of them, neither the cirrhotic patients nor controls received mineral supplements. Any underlying liver disease was excluded in the control group by both clinical assessment and laboratory tests. The subgroups of patients did not differ significantly in age or gender (Tab. 1). Tables 1 and 2 present detailed demographic, clinical and biochemical characteristics of the patients.

The study was approval by the Local Ethics Committee of the Medical University of Lublin, Poland (KE-0254/349/2015), and all participants gave written informed consent for participation in the study.

Laboratory analysis. The serum concentrations of 3 dimers of platelet derived growth factors PDGF AA, PDGF-BB and PDGF-AB were determined using the appropriate ELISA Kits (Cloud-Clone Corporation, USA) in accordance with the manufacture's instructions. The microplates provided in theses kits were pre-coated with antibodies specific for a particular growth factor. Samples, standards and standard diluents (for the blank sample) were applied onto microwells and incubated for 1 hour at $37^{\circ} \mathrm{C}$. Subsequently, Avidin conjugated to Horseradish Peroxidase (HRP) was added to every microwell onto all 3 microplates and incubated under the same conditions. Next, the TMB substrate was added and coloured products were formed in proportion to the amount of PDGF-AA, PDGF-BB and PDGF-AB. The reaction was stopped by adding sulphuric acid, and immediately afterwards, the absorbance of the yellow product was assessed using an Epoch Microplate Spectrophotometer (BioTek Instrumentals, Inc., Winooski, VT, USA). The sample concentrations of PDGF-AA, PDGF-BB and PDGF-AB were calculated using the appropriate standard curves.

Statistical Analysis. All continuous variables were expressed as mean \pm standard deviation (SD). Before performing statistical analysis, the Shapiro-Wilk test was used to test the variables for normality. The Brown-Forsythe's test was then used to test the equality of variances. Serum titer differences between the study and control group were estimated with the use of the ANOVA single factor test. For assessment of the correlations between variables, r-Pearson correlation 
Table 1. Demographic and clinical characteristics of study and control groups

\begin{tabular}{|c|c|c|c|c|c|}
\hline & \multirow{3}{*}{$\begin{array}{c}\text { Control Group } \\
n=16\end{array}$} & \multicolumn{3}{|c|}{ Alcoholic liver Cirrhosis $(\mathrm{N}=\mathbf{8 0})$} & \multirow{3}{*}{$\begin{array}{l}\text { p value } \\
\text { control/ patients }\end{array}$} \\
\hline & & P-Ch:A & P-Ch:B & P-Ch:C & \\
\hline & & $\mathrm{n}=17$ & $\mathrm{n}=26$ & $\mathrm{n}=21$ & \\
\hline Age [years] & $43.7+/-14.6$ & $50.9+/-14.3$ & $55.6+/-11.3$ & $58.9+/-9.5$ & $p>0,05$ \\
\hline Percentage of males & $56.3 \%$ & $64.7 \%$ & $76.9 \%$ & $66.7 \%$ & $p>0,05$ \\
\hline Body mass $[\mathrm{Kg}]$ & $67.6+/-8.9$ & $70.0+/-13.1$ & $75.4+/-12.0$ & $70.9+/-12.6$ & $p>0,05$ \\
\hline Height $[\mathrm{cm}]$ & $173.0+/-5.9$ & $173.2+1-7.5$ & $174.1+/-9.1$ & $171.7+1-6.3$ & $p>0,05$ \\
\hline Time of alcool abuse [Years] & $\mathrm{n} / \mathrm{a}$ & $12.9+/-5.3$ & $16.3+1-4.2$ & $17.0+/-5.5$ & $\mathrm{P}<0,05$ \\
\hline Ascites [\%] & $\mathrm{n} / \mathrm{a}$ & $31.25 \%$ & $69.23 \%$ & $95.00 \%$ & $\mathrm{P}<0,05$ \\
\hline Esophageal varices [\%] & $\mathrm{n} / \mathrm{a}$ & $23.53 \%$ & $61.54 \%$ & $77.78 \%$ & $\mathrm{P}<0,05$ \\
\hline Encephalopathy [\%] & $\mathrm{n} / \mathrm{a}$ & $17.65 \%$ & $36.00 \%$ & $89.47 \%$ & $\mathrm{P}<0,05$ \\
\hline
\end{tabular}

Table 2. Biochemical characteristics of study and control groups

\begin{tabular}{|c|c|c|c|c|c|}
\hline & \multirow{3}{*}{$\begin{array}{l}\text { Control Group } \\
\qquad n=16 \\
\end{array}$} & \multicolumn{3}{|c|}{ Alcoholic liver Cirrhosis $(\mathrm{N}=80)$} & \multirow{3}{*}{$\begin{array}{c}\text { p value } \\
\text { control/ patients }\end{array}$} \\
\hline & & P-Ch:A & P-Ch:B & P-Ch:C & \\
\hline & & $\mathrm{n}=17$ & $\mathrm{n}=26$ & $\mathrm{n}=21$ & \\
\hline Bilirubin [mg/dl] & $\mathrm{n} / \mathrm{a}$ & $4.57+/-9.50$ & $4.41+/-4.91$ & $9.66+/-9.09$ & $p<0,05$ \\
\hline Albumin [g/dl] & $\mathrm{n} / \mathrm{a}$ & $3.47+1-0.77$ & $3.04+1-0.54$ & $2.39+1-0.39$ & $p<0,05$ \\
\hline INR & $\mathrm{n} / \mathrm{a}$ & $1.17+/-0.30$ & $1.46+1-0.29$ & $1.91+/-0.64$ & $p<0,05$ \\
\hline Platelets [G/I] & $231.36+/-29.82$ & $200.76+/-110.58$ & $139.42+/-80.85$ & $145.29+/-80.99$ & $p<0,05$ \\
\hline Mean cell volume [fl] & $84.79+/-3.49$ & $91.32+/-7.88$ & $88.52+/-11.39$ & $95.01+/-9.14$ & $p<0,05$ \\
\hline Urea [mg/dl] & $\mathrm{n} / \mathrm{a}$ & $32.10+1-20.38$ & $25.47+/-14.07$ & $46.73+/-40.51$ & $p<0,05$ \\
\hline Sodium [mmol/l] & $140.00+/-3.28$ & $134.50+/-4.38$ & $134.81+/-4.14$ & $133.50+/-6.13$ & $p<0,05$ \\
\hline Potasium [mmol/l] & $4.39+1-0.39$ & $4.21+1-0.57$ & $4.07+1-0.46$ & $3.84+l-0.59$ & $\mathrm{p}<0,05$ \\
\hline C-reactive protein [mg/l] & $2.51+/-2.29$ & $8.79+/-11.37$ & $21.56+/-21.30$ & $26.66+/-21.47$ & $p<0,05$ \\
\hline
\end{tabular}

coefficients were calculated. All qualitative variables were expressed in percentage, as indicators of structure. The Kruskal Wallis $\chi 2$ test was used for intergroup comparisons. For all tests, $p$ value $<0.05$ was assumed as statistically significant. All calculations were performed using SPSS Statistics Software, IBM.

\section{RESULTS}

PDGF-AA concentrations. The serum levels of PDGF-AA in alcoholic cirrhotic patients were significantly higher than those in the healthy individuals $(\mathrm{p}=0.034)$. The highest concentrations of PDGF-AA were present in Child-Pugh C patients $(24.48 \pm 9.52 \mathrm{ng} / \mathrm{ml})$, followed by Child-Pugh $\mathrm{B}$ $(20.67 \pm 11.24 \mathrm{ng} / \mathrm{ml})$, and A (17.43 $\pm 9.72 \mathrm{ng} / \mathrm{ml})$ patients, compared to controls $(15.13 \pm 6.27 \mathrm{ng} / \mathrm{ml})$. The Pearson's correlation test showed statistically important correlations of PDGF-AA values in different cirrhotic patients compared to controls $(\mathrm{R}=0.26 ; \mathrm{p}=0.038)$. The non-parametric Kruskal Willis test showed the high level of intergroup differences in PDGF-AA results in cirrhotic patients $(\chi 2=5.82)$ with no important statistical difference (marginal $\mathrm{p}=0.054$ ).

PDGF-BB concentrations. The serum levels of PDGF-BB were significantly higher in Child-Pugh A $(14.89 \pm 12.41 \mathrm{ng} / \mathrm{ml}), \mathrm{B}$ $(15.74 \pm 12.33 \mathrm{ng} / \mathrm{ml})$, and C $(24.06 \pm 13.66 \mathrm{ng} / \mathrm{ml})$ patients, compared to controls $(1.85 \pm 1.51 \mathrm{mg} / \mathrm{L} ; \mathrm{p}<0.0001$. Pearson's correlation test also showed statistically important correlations of PDGF-BB values in different cirrhotic patients, compared to controls $(\mathrm{R}=0.28 ; \mathrm{p}=0.027)$. Kruskal Willis test showed important intergroup differences in PDGF-BB levels in cirrhotic patients $\left(\mathrm{p}=0.029, \chi^{2}=7.11\right)$.

PDGF-AB concentrations. There was no statistical difference in the serum concentration of PDGF-AB between cirrhotic patients and controls. Its level amounted to $3.79 \pm 1.15 \mathrm{ng} / \mathrm{ml}$ in Child-Pugh A, $3.77 \pm 1.63 \mathrm{ng} / \mathrm{ml}$ in group B, and 3.92 $\pm 1.14 \mathrm{ng} /$ $\mathrm{ml}$ in group C patients, compared to controls $(3.36 \pm 0.72 \mathrm{mg} / \mathrm{L}$; $\mathrm{p}>0.05$. No statistically significant differences of PDGF-AB serum concentrations were demonstrated between particular groups of liver cirrhosis.

The serum levels of different dimers of PDGFs are summed up in Table 3 and Figures 1-3.

PDGF dimers clinical and laboratory correlations. Analysis between the subgroups of cirrhotic patients showed positive correlations between the serum level of PDGF-AA and PDGF-BB and stages of liver cirrhosis (Pugh-Child) $(\mathrm{R}=0.26$; $\mathrm{p}=0.038$ and $\mathrm{R}=0.28 ; \mathrm{p}=0.027$, respectively). Furthemore, PDGF-AA correlated negatively with platelet, INR levels and encephalopathy diagnosis in cirrhosis patients $(\mathrm{p}=0.001$, $\mathrm{p}<0.05$ and $\mathrm{p}=0.004$, respectively). PDGF-BB correlated statistically with the serum levels of albumin $(\mathrm{p}<0.05)$, bilirubin ( $\mathrm{p}=0.001)$, ASP, urea and CRP $(\mathrm{p}<0.05)$, as well as with the presence of encephalopathy $(\mathrm{p}<0.05)$. 
Table 3. PDGFs subgroups serum levels in studied groups

\begin{tabular}{|c|c|c|c|c|c|}
\hline & \multirow{2}{*}{ Control Group } & \multicolumn{3}{|c|}{ Alcoholic liver Cirrhosis $(\mathrm{N}=\mathbf{8 0})$} & \multirow{2}{*}{ p value } \\
\hline & & P-Ch:A & P-Ch:B & P-Ch:C & \\
\hline & $\mathrm{n}=16$ & $\mathrm{n}=17$ & $\mathrm{n}=26$ & $\mathrm{n}=21$ & control/ patients \\
\hline PDGF AA [ng/ml] & $15.13+/-6.3$ & $17.43+/-9.7$ & $20.67+/-11.2$ & $24.48+/-9.5$ & $p=0,034$ \\
\hline PDGF BB [ng/ml] & $1.85+/-1.5$ & $14.89+/-12.4$ & $15.74+/-12.3$ & $24.06+/-13.7$ & $p<0,0001$ \\
\hline PDFG AB [ng/ml] & $3.36+/-0.7$ & $3.79+/-1.2$ & $3.77+/-1.6$ & $3.92+/-1.1$ & $p>0,05$ \\
\hline
\end{tabular}

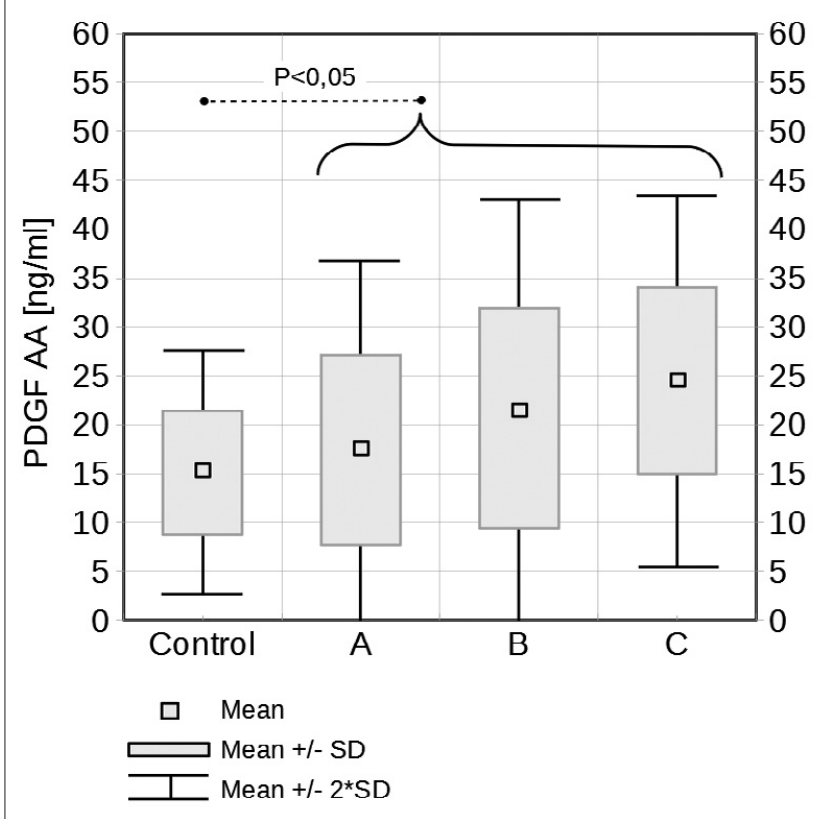

Figure 1. PDGF AA serum levels in patients with different stages of liver cirrhosis and controls

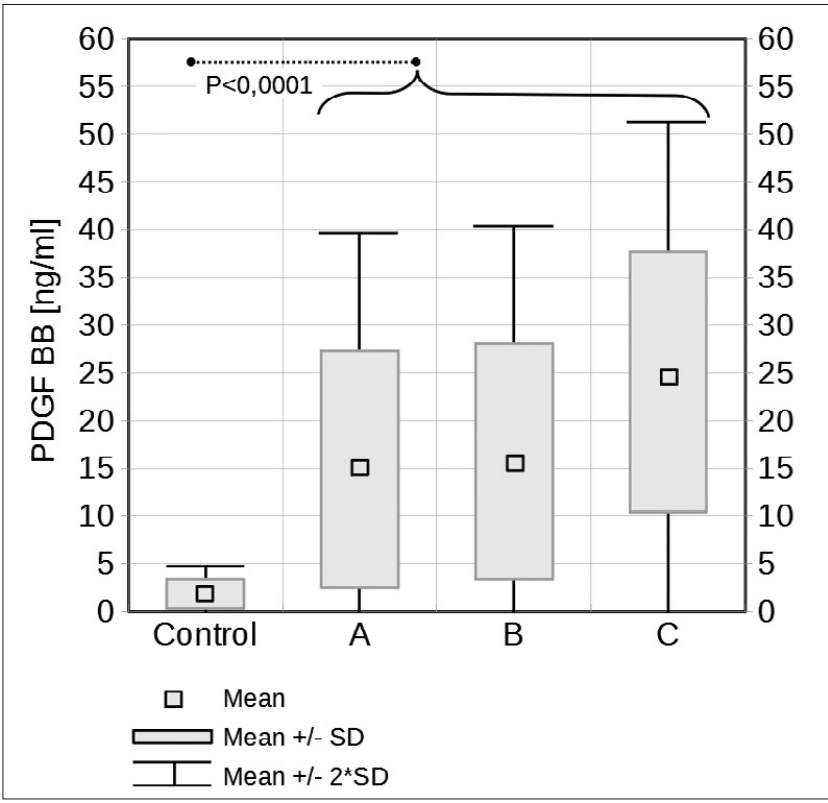

Figure 2. PDGF BB serum levels in patients with different stages of liver cirrhosis and controls

\section{DISCUSSION}

Non-invasive diagnosis of hepatic fibrosis is becoming very important and promising, especially in limited liver biopsy.

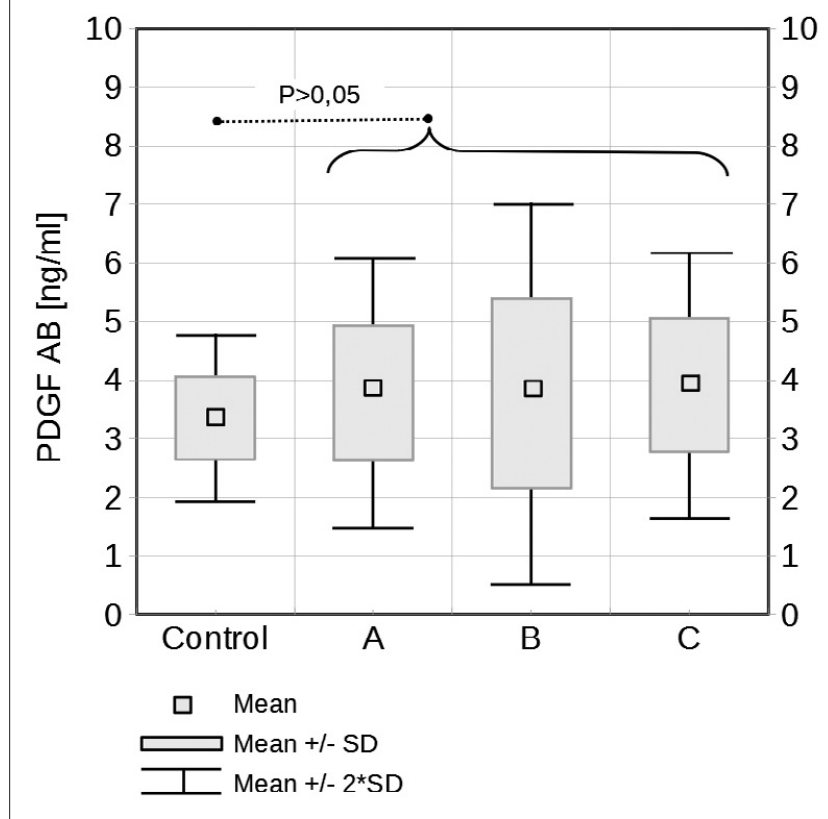

Figure 3. PDGF AB serum levels in patients with different stages of liver cirrhosis and controls

It plays an especially important role in the surveillance of treatment and in screening for hepatic fibrosis. Even though the pathogenesis of hepatic fibrosis is still unclear, early diagnosis and treatment of this pathology would help markedly diminish the mortality rate of patients. Plateletderived growth factors (PDGFs) are cytokines that together with the necrosis factor- $\alpha$ (TNF- $\alpha$ ), transforming growth factor $\beta 1$ (TGF- $\beta 1$ ) and the ECM, play an important role in hepatic fibrogenesis [7-10]. Among these common cell regulators, PDGFs are the most powerful elements involved in stimulating HSC proliferation, differentiation, and migration. They also stimulate collagen production and deposition, and transform HSCs into myofibroblasts [14]. Blocking PDGF signaling has been found to inhibit HSC proliferation and ameliorate liver fibrogenesis [16]. It has also been observed in clinical studies that stimulation of PDGFs and their downstream molecules seems to be associated with the activation of necroinflammation and fibrosis in patients with hepatic damage [13-15]. Therefore, the PDGF signaling pathway is certainly crucial in the advancement and further prognosis of hepatic fibrosis.

The current study shows that the plasma levels of PDGF$\mathrm{AA}$ and PDGF-BB homodimers increased significantly in patients with alcoholic liver cirrhosis, whereas the plasma level of PDGF-AB heterodimer did not show such a relationship. When the stage of the disease increased, so did the concentrations of PDGF-AA and PGFD-BB in blood. Furthermore, it was observed that the serum level of both 
PDGF-AA and PDGF-BB correlated significantly with the severity of alcoholic liver cirrhosis (measured by Pugh-Child's scale). It must be stressed that the correlation between the extent of the severity of alcoholic liver cirrhosis was stronger in the case of the dimer PDGF-BB levels than in PDGF-AA $(\mathrm{R}=0.28 ; \mathrm{p}=0.027$ and $\mathrm{R}=0.26 ; \mathrm{p}=0,038$, respectively). The non-parametric Kruskal Willis test showed the high level of inter-group differences in PDGF-AA results in cirrhotic patients $(\chi 2=5.82)$ compared to controls, but with a tendency but a non-important statistical difference between the subgroups of cirrhotic patients (marginal $\mathrm{p}=0.054$ ).

To the best of the knowledge of the authors of the presented study, this is the first clinical study to concentrate on assessment of the plasma levels of PDGFs in patients with alcoholic liver cirrhosis. The obtained results are consistent with the data found in other causes of liver cirrhosis. Diang et al. analysed chronic hepatitis $\mathrm{B}(\mathrm{CHB})$ patients and found that the serum concentrations of PDGF-BB homodimer could reflect the extent of liver damage and liver fibrosis in those patients [11]. The authors found that liver function parameters and serum liver fibrosis markers were significantly correlated with serum PDGF-BB. Furthermore, liver fibrosis markers and serum concentrations of PDGF-BB in $\mathrm{CHB}$ were positively correlated with the extent of liver damage. Suprisingly, Diang et al. also stated that serum concentrations of PDGF-BB in HBeAg-negative $\mathrm{CHB}$ were even significantly higher than those in the $\mathrm{HBeAg}$-positive CHB. Tanikawa et al. evaluated the expressions of PDGF-A, PDGF-B, and TGF- $\beta 1$ in hepatic tissue and platelets from HCV-infected patients who had different degrees of hepatic fibrosis [12]. They found that the mRNA expression of PDGF-A in platelets differed depending on the degree of liver fibrosis. Patients with advanced fibrosis had significantly higher PDGF-A mRNA expressions than patients with early-stage fibrosis. Furthermore, TGF- $\beta 1$ was more frequently expressed in platelets than in liver tissue, and vice versa for PDGF-B. Tanikawa et al. conclude that the stimulation of HSCs leading to fibrosis could be caused by PDGF-A mRNA expression from megakaryocytes, involving the TGF- $\beta 1$ signaling pathway. In the current study of alcoholic liver cirrhosis, high serum concentrations of PDGF-AA dimers were found which differed less importantly from the controls. Analysis between subgroups of cirrhotic patients, however, showed positive correlations between the serum level of PDGF-AA and stages of liver cirrhosis (Pugh-Child), just as in the case of PDGF-BB levels in the alcoholic patients in the current study.

PDGF-B isoform is recognised as the most important mitogen for HSCs. This might also be caused by the fact that PDGF-BB binds with all subunits of PDGF receptors (PDGFR- $\alpha \alpha,-\alpha \beta$ and $-\beta \beta$ ), and therefore its biological effect is more important $[7-10,17]$. This study of alcoholic liver cirrhosis confirms that both dimers - PDGF-AA and PDGF-BB - are important, and their levels increase in serum compared to controls, whereas this is not true for the dimer PGDF-AB.

Liver cirrhosis is a serious disease involving considerable mortality [18]. Multiple clinical studies with hepatic patients evidence that the reduction and even the reversal of fibrosis is achievable with effective treatment of the underlying disease [19]. Marcellin et al. have shown that treatment of viral B hepatitis leads to a reversal of established cirrhosis in most patients [20]. Poynard et al. have also obtained good results in the treatment of viral $\mathrm{C}$ hepatitis [21]. The treatment of many non-viral liver diseases, however, is more difficult, and in such cases an adequate anti-fibrotic drug could help in a large number of patients $[16,18]$. Recent studies outline the importance of anti-fibrotic drugs acting via inhibition of PDGFs, especially its isoform B and A [22-24]. The current study proves the importance of PDGF-BB and PGDF-AA homodimers in alcoholic liver cirrhosis, which could be considered as possible treatment target of anti-fibrotic theraphy.

Limitations of the study. Firstly, this was a single-centre study and the relatively small number of studied individuals and control subjects were insufficient to arrive at final conclusions; therefore, further prospective studies in a large population of liver cirrhosis are needed. The study involved only patients with alcoholic liver cirrhosis; thus, it cannot be determined whether the observed relationships could also concern other groups of patients with different causes of liver cirrhosis.

\section{CONCLUSIONS}

The serum level of PDGF-AA and PDGF-BB homodimers increases in patients with alcoholic liver cirrhosis, unlike the serum level of PDGF-AB heterodimer. Furthermore, the serum level of both PDGF-AA and PDGF-BB correlates significantly with the stage of alcoholic liver cirrhosis (PughChild), the correlation being stronger in the case of PDGF-BB levels than PDGF-AA. The plasma levels of PDGF-AA and -BB seem to be good indicators of the alcohol-induced liver fibrosis process, and might be considered as possible future treatment targets. This is especially true for serum PDGFBB levels that also show important inter-group differences in cirrhotic patients. Further prospective studies are needed to fully explain the role of these homodimers in different groups of patients with liver cirrhosis.

\section{REFERENCES}

1. Blachier M, Leleu H, Peck-Radosavljevic M, Valla D-C, Roudot Thoraval F. The burden of liver disease in Europe: A review of available epidemiological data. J Hepatol. 2013; 25(3): 593-608.

2. World Health Organization. European status report on alcohol and health: World Health Organization. Regional Office for Europe, 2010.

3. Plewka K, Szuster-Ciesielska A, Kandefer-Szerszeń M. Role of stellate cells in alcoholic liver fibrosis. Postepy Hig Med Dosw. 2009; 63: 303-317.

4. Reeves HL, Friedman SL. Activation of setellate cells - a key issue in liver fibrosis. Front Biosci. 2002; 7: d808-d826.

5. Zhou W-C, Zhang Q-B, Qiao L. Pathogenesis of liver cirrhosis. World J Gastroenterol. 2014; 20(23): 7312-7324.

6. Zhang BB, Cai WM, Weng HL, Hu ZR, Lu J, Zheng M, et al. Diagnostic value of platelet derived growth factor- $B B$, transforming growth factor-b1, matrix metalloproteinase-1, and tissue inhibitor of matrix metalloproteinase- 1 in serum and peripheral blood mononuclear cells for hepatic fibrosis. World J Gastroenterol. 2003; 9(11): 2490-2496.

7. Hua-Zhong Y, Qin Ch, Wen-You Z et al. PDGF signaling pathway in hepatic fibrosis pathogenesis and therapeutics (Review). Molecular Med Rep. 2017; 16: 7879-7889.

8. Fredriksson L, Li H and Eriksson U: The PDGF family: Four gene products from five dimeric isoforms. Cytokine Growth Factor Rev. 2004; 15: 197-204.

9. Betsholtz C. Biology of platelet-derived growth factors in development. Birth Defects Res C Embryo Today. 2003; 69(4): 272-85.

10. Breitkopf K, van Roeyen CV, Sawitza I, Wickert L, Floege J, Gressner AM. Expression patterns of PDGF-A, -B, -C and -D and the PDGFreceptors alpha and beta in activated rat hepatic stellate cells (HSC). Cytokine. 2005; 31(5): 349-57. 
11. Diang XC1, Ma LN, Li YF, Liu XY, Zhang X, Liu JY et al. Association between serum platelet-derived growth factor $\mathrm{BB}$ and degree of liver damage, fibrosis and hepatitis $\mathrm{B}$ e antigen ( $\mathrm{HBeAg}$ ) status in $\mathrm{CHB}$ patients. Hepatogastroenterology. 2012; 59(120): 2357-60.

12. Tanikawa AA, Tommasini Grotto RM, Faria Silva G, Camargo Ferrasi A, Rodrigues Sarnighausen VC, de Moura Campos Pardini MI. Plateletderived growth factor A mRNA in platelets is associated with the degree of hepatic fibrosis in chronic hepatitis C. Rev Soc Bras Med Trop. 2017; 50(1): 113-116.

13. Folestad E, Kunath A, Wagsater D. PDGF-C and PDGF-D signaling in vascular diseases and animal models. Molecular Aspect Med. 2018; 62: 1-11.

14. Klinkhammer BM, Floege J, Boor P. PDGF in organ fibrosis. Molecular Aspect Med. 2017; 1-19.

15. Pugh R, Murray-Lyon I, Dawson J, Pietroni M, et al. Transection of the oesophagus for bleeding oesophageal varices. Br J Surg. 1973; 60(8): 646-9.

16. Papadopoulos N, Lennartsson J. The PDGF/PDGFR pathway as a drug target. Molecular Aspects Med. 2017: 1-14.

17. Thieringer F, Maass T, Czochra P, Klopcic B, Conrad I, Friebe D, et al. Spontaneous hepatic fibrosis in transgenic mice overexpressing PDGF-A. Gene. 2008; 423(1): 23-28.
18. Friedman SL. Liver fibrosis e from bench to bedside. J. Hepatol. 2003; 1(38): S38-S53.

19. Zoubek ME, Trautwein C, Strnad P. Reversal of liver fibrosis: from fiction treality. Best Pract Res Clin Gastroenterol. 2017; 31(2): 129-141.

20. Marcellin P, Gane E, Buti et al. Regression of cirrhosis during treatment with tenofovir disoproxil fumarate for chronic hepatitis B: a 5-year open-label follow-up study. Lancet 2013; 381 (9865): 468-475.

21. Poynard T, McHutchison J, Manns et al. Impact of pegylated interferon alfa-2b and riba-virin on liver fibrosis in patients with chronic hepatitis C. Gastroenterology 2002; 122(5): 1303-1313.

22. Van Dijk F, Olinga P, Poelstra K and Beljaars L. Targeted therapies in liver fibrosis: combining the best parts of platelet-derived growth factor BB and interferon gamma. Frontiers in Medicine 2015; 2: 72.

23. Ruchi Shah, Karina Reyes-Gordillo and Marcos Rojkind. Thymosin $\beta 4$ inhibits PDGF-BB induced activation, proliferation, and migration of human hepatic stellate cells via its actin-binding domain. Exp Opinion Biol Ther. 2018;18:sup1: 177-184.

24. Borkham-Kamphorst E, Weiskirchen R. The PDGF system and its antagonists in liver fibrosis, Cytokine Growth Factor Rev. 2016; 28 : 53-61. 